\title{
PENGEMBANGAN MATERI AJAR BAHASA INGGRIS UNTUK MEMFASILITASI PEMBELAJARAN OTENTIK MENGGUNAKAN"VIRTUAL REALITY" BAGI DIGITAL NATIVES
}

\author{
Qory Halizatul Fhathah, Wahyunia, Akmal Fathulloh \\ qory246@gmail.com \\ Mahasiswa Fakultas Keguruan dan Ilmu Pendidikan Universitas Ibn Khaldun
}

\begin{abstract}
ABSTRAK
Pemahaman siswa terhadap materi ajar dalam kelas merupakan hal penting dalam kegiatan pembelajaran. Namun, dalam penerapannya masih terdapat siswa yang mengalami kesulitan dalam memahami materi ajar. Guru harus menemukan media untuk mendukung kegiatan pembelajaran. Virtual reality (VR) merupakan teknologi mutakhir yang memiliki potensi tinggi jika diterapkan dalam ranah pendidikan. Virtual reality (VR) dapat memberikan pengalaman pemahaman secara visual agar siswa dapat memahami materi ajar secara lebih detail dan mendalam. Penelitian ini melibatkan 6 responden yang merupakan mahasiswi program studi Pendidikan Bahasa Inggris. Hasil penelitian menunjukkan bahwa penggunaan virtual reality (VR) terhadap materi ajar bagi murid digital native efektif dilaksanakan, dengan di latar belakangi oleh beberapa alasan para responden.
\end{abstract}

Kata Kunci: Virtual reality, materi ajar, pemahaman siswa, digital natives

\section{PENDAHULUAN}

Materi ajar adalah seperangkat bahan ajar yang dipersiapkan guru dalam kegiatan belajar mengajar dikelasnya. Tomlinson (1998) dalam Wahyanti \& Sutopo (2012) mengatakan bahwa materi ajar adalah segala bentuk materi yang digunakan untuk membantu guru dalam melaksanakan kegiatan belajar mengajar. Menurut Wahyanti \& Sutopo (2012), materi ajar harus menarik dan menyenangkan dan banyak latihan mengucapkan atau berbicara. Maka, kehadiran media pengajaran untuk mendukung pemahaman siswa dalam memahami materi sangat diperlukan adanya. Virtual reality adalah satu media yang dapat membantu pengembangan materi ajar dalam kegiatan belajar mengajar.

Virtual reality (VR) merupakan teknologi mutakhir yang memiliki potensi tinggi jika diterapkan dalam ranah pendidikan. Menurut kamus Oxford, VR adalah gambar-gambar yang muncul mengelilingi orang yang menggunakan VR dan membuatnya terlihat nyata. VR menciptakan ilusi seolah animasi yang ditampilkan lebih nyata. Menurut Rheingold (1991), Virtual reality (VR) merupakan teknologi yang mengubah dan menawarkan sudut pandang baru mengenai tujuan inti dari pendidikan. Kehadiran VR dapat menambah variasi media pembelajaran bagi pendidikan di abad 21 . Pengimplementasian VR dalam kelas dapat 
menyokong kelas yang lebih efektif dan mendukung realisasi dari pembelajaran otentik yang bersifat nyata.

Pembelajaran otentik adalah pembelajaran yang erat kaitannya dengan dunia nyata, dan dalam pengaplikasiannya menerapkan studi kasus, aktivitas berbasis masalah serta latihan bermain peran agar pembelajaran terasa lebih nyata dan hidup. Har (2013) mengatakan bahwa pembelajaran otentik merupakan pembelajaran yang terjadi dengan keikutsertaan siswa dalam masalahmasalah, bagaimana memecahkan masalah yang rumit serta penemuan solusi dari masalah tersebut, dan pada saat yang sama, siswa berlatih kemampuan serta pengetahuan yang relevan dan nyata dengan situasi didalam kelasnya. Menurut Tomlinson (2011), tugas otentik merupakan tugas yang melibatkan penggunaan bahasa oleh peserta didik dengan cara mereplikasi penggunaannya di 'dunia nyata' diluar kelas bahasa.

\section{METODE PENELITIAN}

Metode kualitatif diterapkan oleh peneliti untuk mendeskripsikan perkembangan materi ajar bahasa Inggris menggunakan virtual reality untuk memfasilitasi pembelajaran otentik bagi murid digital native. Responden dari penelitian ini merupakan 6 orang mahasiswi Program Studi Pendidikan Bahasa Inggris Fakultas Keguruan dan Ilmu Pendidikan di Universitas Ibn Khaldun Bogor. Penelitian ini dilaksanakan pada tanggal 18-26 Desember 2019.

Peneliti menggunakan video virtual reality $360^{\circ}$ di channel Youtube milik National Geographic sebagai materi ajar.
Pendidikan abad 21 berkaitan erat dengan teknologi dan keikutsertaan generasi millennial atau digital native dalam kelas, yang didalamnya terdapat pembelajaran otentik.

Digital native adalah anak-anak yang terlahir fasih menggunakan bahasa komputer, video games, dan internet (Prensky, 2001). Prensky (2001) juga mengatakan bahwa rata-rata lulusan sarjana menghabiskan kurang dari 5.000 jam hidup mereka untuk membaca, tapi lebih dari 10.000 jam untuk bermain video games (angka ini belum termasuk 20.000 jam untuk menonton TV). Hal ini semakin memperkuat pernyataan bahwa digital native merupakan generasi yang terbiasa menggunakan teknologi untuk mengerjakan banyak hal, termasuk dalam pembelajaran. Penelitian ini bertujuan untuk mengetahui perkembangan materi ajar bahasa Inggris menggunakan virtual reality untuk memfasilitasi pembelajaran otentik bagi murid digital natives.

Video dengan judul $360^{\circ}$ Great Hammerhead Shark Encounter | National Geographic ini belum pernah ditonton oleh keenam responden sebelumnya. Sebelum melakukan uji coba terhadap VR, peneliti mengajukan beberapa pertanyaan yang berkaitan dengan penggunaan VR dan materi ajar Bahasa Inggris. Hal ini dilakukan agar peneliti dapat mengetahui pengalaman responden terhadap penggunaan VR serta mengetahui opini mereka mengenai materi ajar. Berikut merupakan tangkapan layar (screenshot) dari video yang digunakan oleh peneliti. menggunakan Virtual reality. 

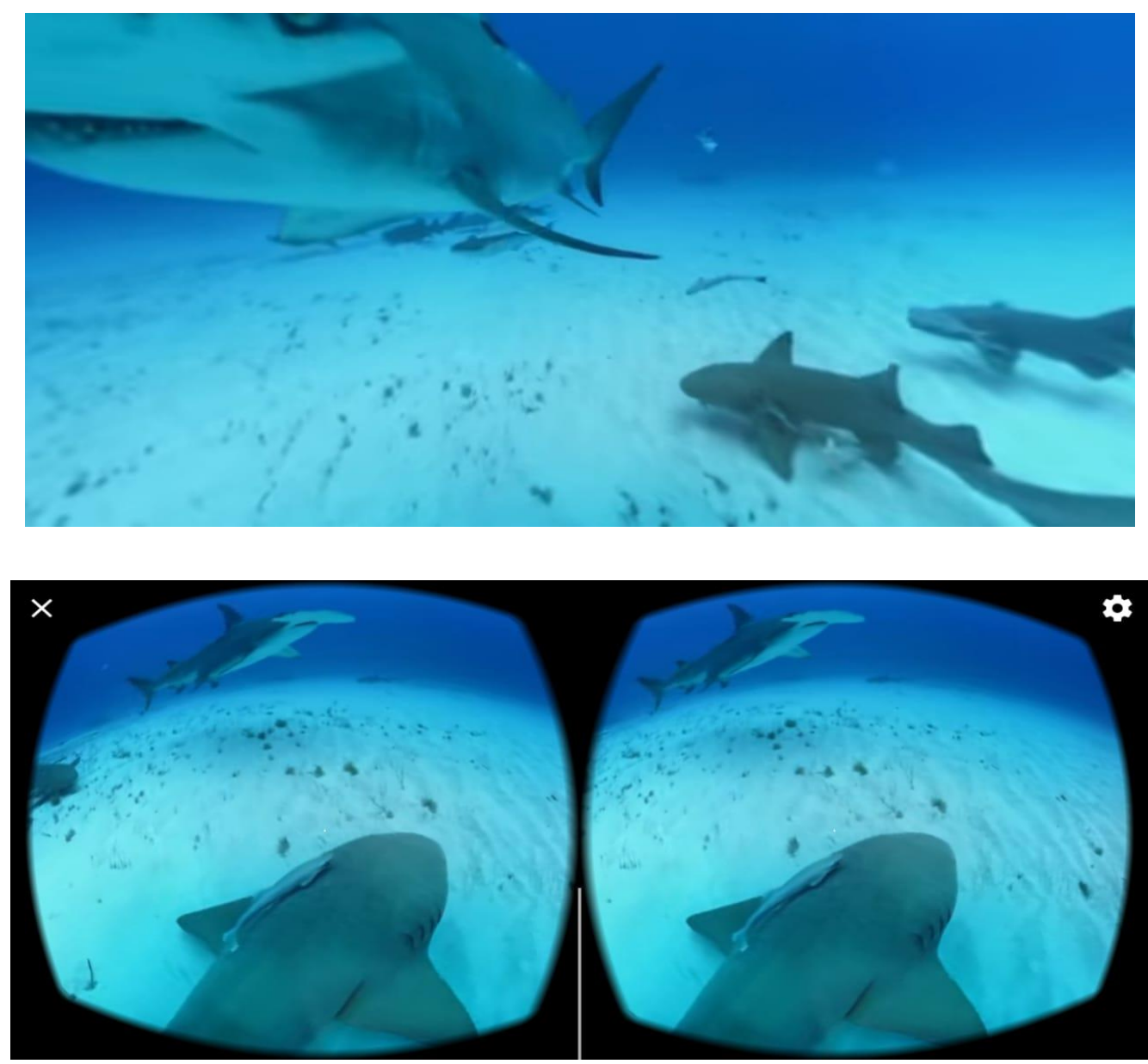

Selanjutnya, keenam responden penggunaan VR. Berikut adalah secara bergantian melakukan uji coba penggunaan virtual reality (VR) terhadap materi ajar. Peneliti melakukan observasi terhadap reaksi responden mengenai dokumentasi ketika responden melakukan uji coba penggunaan virtual reality (VR) terhadap materi ajar.

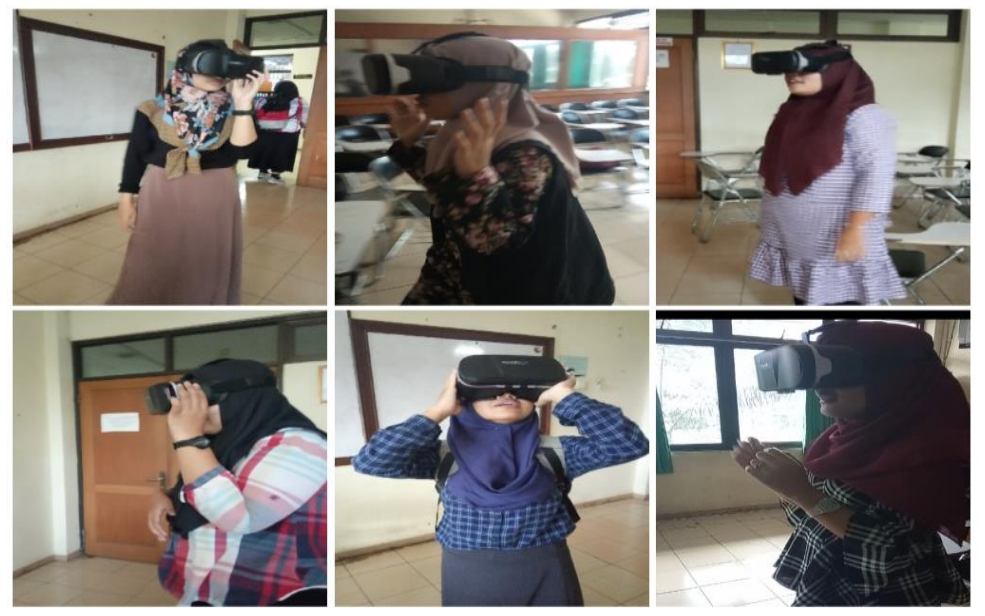

Peneliti menggunakan wawancara (interview) sebagai metode pengolahan data untuk penelitian ini. Wawancara merupakan teknik pengumpulan data 
dalam metode survai yang menggunakan pertanyaan secara lisan kepada subjek pemeriksaan (BPKP, 2007). Dalam interview ini, peneliti mengajukan beberapa pertanyaan yang berkaitan

\section{HASIL PENELITIAN}

Interview digunakan oleh peneliti sebagai metode pengumpulan data. Peneliti mengajukan 6 buah pertanyaan kepada para responden penelitian ini. Dari dengan pengetahuan mereka mengenai materi ajar dan penggunaan VR dengan jawaban yang berasal dari pendapat para responden.

1. Apakah anda bisa menjelaskan tentang "dive with shark"?

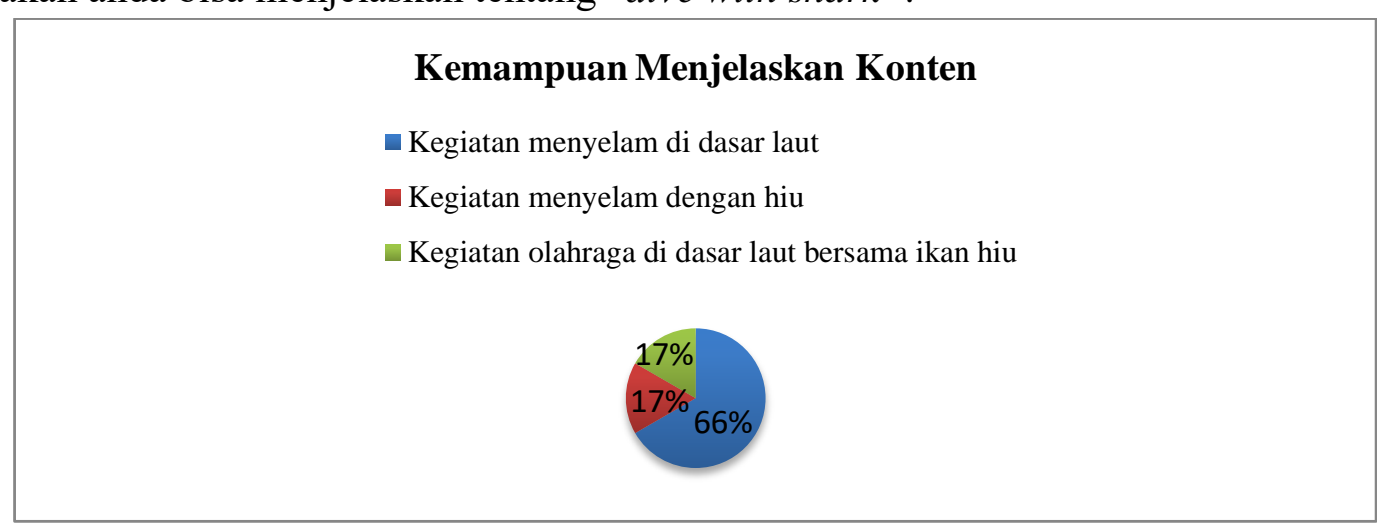

2. Apakah anda memiliki kesulitan dalam menjelaskan deskripsi mengenai "dive with shark?"

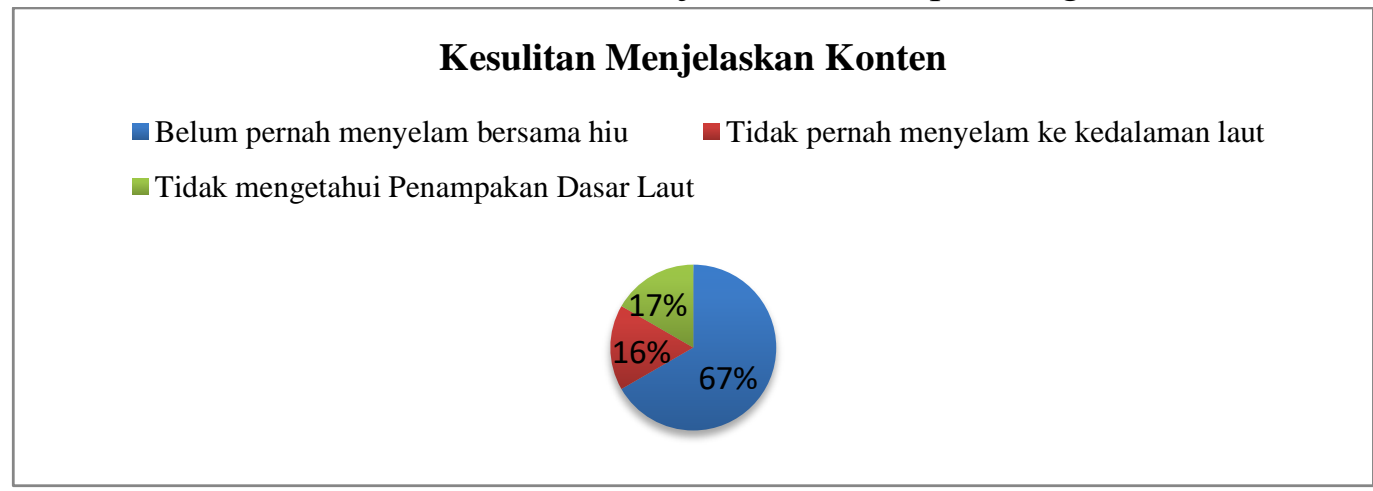

3. Apakah anda pernah menggunakan VR sebelumnya?

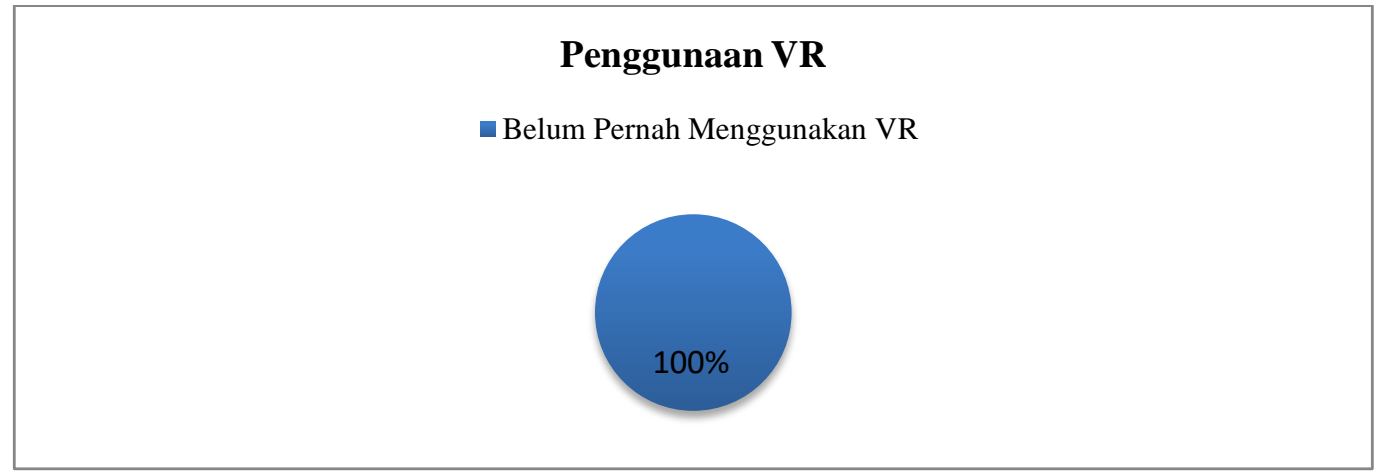

4. Apakah anda merasakan perbedaan ketika menjelaskan "dive with shark" dengan dan tanpa bantuan VR? 


\section{Menjelaskan Konten Dengan dan Tanpa VR}

- VR mempermudah mereka dalam menjelaskan isi konten

- Pengalaman seperti berada dalam laut

- Tanpa alasan

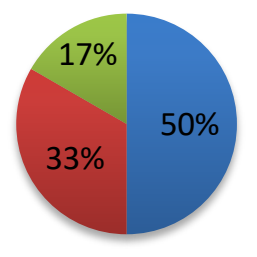

5. Apakah, materi "dive with shark" menjadi lebih jelas dan membantu anda untuk menjelaskan secara detail dengan menggunakan VR?

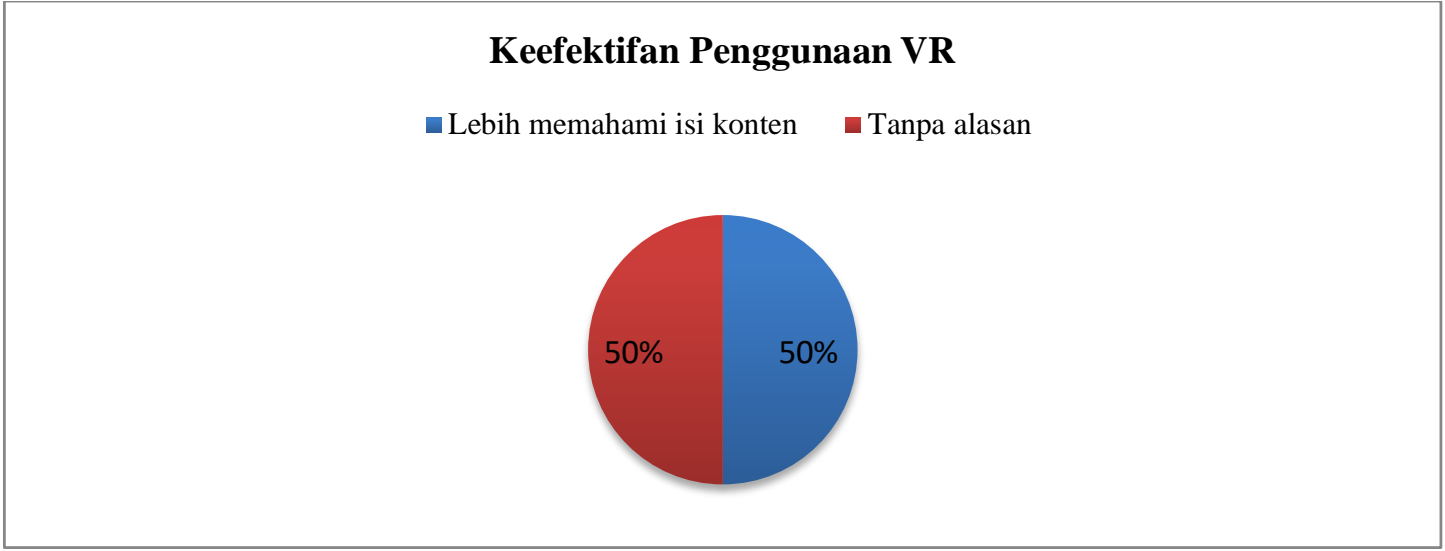

6. Bagaimana kesan anda setelah menggunakan VR?

\begin{tabular}{|c|c|} 
& Kesan Setelah Menggunakan VR \\
$\square$ Pengalaman Baru $\quad$ - Memahami konten lebih rinci $\quad$ - Menggambarkan konten lebih jelas \\
\hline
\end{tabular}

\section{PEMBAHASAN}

Berdasarkan hasil wawancara (interview) dapat ditarik beberapa kesimpulan yakni sebagai berikut, hasil interview pertama mengenai kemampuan responden menjelaskan konten menunjukkan bahwa seluruh responden dapat menjelaskan konten dengan baik, namun mereka memiliki definisi menurut

perspektif masing-masing. Sebanyak $66 \%$ responden menjawab bahwa dive with shark merupakan kegiatan menyelam bersama hiu. Seperti yang dipaparkan oleh responden a, "Menurut saya, dive with shark adalah salah satu kegiatan olahraga menyelam ke dalam laut". Sedangkan sebanyak $17 \%$ responden menjawab bahwa 
dive with shark merupakan kegiatan olahraga di dasar laut bersama ikan hiu.seperti yang dipaparkan oleh responden f, "Dive with shark adalah kegiatan olahraga di dasar laut bersama ikan hiu".

Hasil interview kedua mengenai kesulitan yang dialami responden dalam mendeskripsikan konten sebelum menggunakan VR menunjukkan bahwa seluruh responden mengalami kesulitan dengan alasan yang berbeda. Sebanyak $67 \%$ responden mengalami kesulitan dalam menjelaskan konten karena mereka belum pernah menyelam bersama hiu sebelumnya. Seperti yang dipaparkan oleh responden d, "Saya mengalami kesulitan menjawab apa itu dive with shark, karena saya belum pernah mencoba merasakan berenang bersama hiu". Sedangkan, sebanyak $17 \%$ responden mengalami kesulitan karena mereka tidak mengetahui seperti apa penampakan dasar laut sebelumnya. Seperti yang dipaparkan oleh responden $f$, "Ya saya mengalami kesulitan, karena saya sendiri belum tahu betul seperti apa penampakan dasar laut, saya hanya tahu bagaimana permukaannya saja".

Dalam butir interview ketiga yang menanyakan perihal pengalaman para responden tentang penggunaan VR, seluruh responden menjawab bahwa mereka belum pernah menggunakan VR sebelumnya. Hasil interview keempat yang menanyakan perbedaan dalam menjelaskan isi konten menunjukkan bahwa seluruh responden merasakan perbadaan tersebut, namun memiliiki opini beragam. Sebanyak $50 \%$ responden mengatakan bahwa VR mempermudah mereka dalam menjelaskan isi konten. Seperti yang dikatakan oleh responden e, "Dengan bantuan VR saya bisa lebih mudah menjelaskannya karena terlihat seperti nyata". Sedangkan sebanyak 33\% responden menjawab bahwa VR memberikan mereka pengalaman seperti berada didalam laut. Seperti yang dipaparkan oleh responden c, "Dengan memakai VR, saya merasakan pengalaman dive with shark secara langsung".

Hasil interview kelima yang menanyakan keefektifan penggunaan VR menunjukkan konten pembelajaran lebih jelas dan detail. Sebanyak 50\% responden menjawab tanpa alasan, sedangkan 50\% responden menjawab bahwa dengan VR, mereka lebih memahami isi konten. Seperti yang dikatan oleh responden b, "Jika tidak menggunakan VR, saya mengalami kesulitan menjelaskan karena tidak tahu seperti apa rasanya".

Butir interview keenam yang menanyakan kesan para responden setelah menggunakan VR menunjukkan bahwa seluruh responden membagikan kesan positif setelah menggunakan VR. Sebanyak $67 \%$ responden menjawab bahwa VR memberikan pengalaman baru kepada mereka. Responden a menjawab, "Kesan yg saya dapatkan adalah pengalaman baru secara visual kepada bentuk yang sifatnya maya sehingga objek yg sebenarnya tidak ada bisa kita rasakan hanya melalui penglihatan". Sedangkan sebanyak $16 \%$ responden menjawab bahwa mereka dapat memahami konten secara lebih rinci, seperti yang dipaparkan oleh responden b, "Setelah menggunakan VR, saya lebih mengerti mengenai dive with shark secara rinci, saya jadi bisa merasakan pengelaman menegangkannya berenang bersama

hiu". 


\section{KESIMPULAN}

Pemahaman siswa terhadap materi ajar adalah hal penting dalam kegiatan pembelajaran. Banyak materi ajar yang bagus dan relevan namun tetap banyak siswa yang mengalami kesulitan dalam memahami materi. Untuk mengantisipasi hal tersebut, guru harus menemukan media ajar yang menarik. Penggunaan virtual reality (VR) yang menawarkan pengalaman pemahaman secara visual dalam kegiatan pembelajaran dapat menjadi solusinya. Hasil studi mengungkapkan bahwa virtual reality dapat membantu mereka dalam

\section{DAFTAR PUSTAKA}

C. Murni Wahyanti, Joko Sutopo. 2012. Pengembangan Materi Ajar Berbasis Pendidikan Karakter Bagi Guru Bahasa Inggris SD Di Kecamatan Tembalang. Fakultas Bahasa dan Seni, Universitas Negeri Semarang

Dr Lam Bick Har . 2013. Authentic Learning. The Hong Kong Institute of Education All rights reserved. www.ied.edu.hk/aclass/

Mahpur, Mohammad. 2017. Memantapkan Analisis Data Kualitatif Melalui Koding. Universitas Negeri Malang

Marc Prensky. 2001. Digital Natives, Digital Immigrants. MCB University Press, Vol. 9 No. 5

Nagy, Adam and Attila Kölcsey. 2017. Generation Alpha: Marketing or memahami materi ajar secara lebih rinci, jelas dan mendalam.

Berkaitan dengan pembelajaran otentik, penggunaan virtual reality dalam pembelajaran bahasa inggris menjadikan pembelajaran menjadi lebih nyata bagi mahasiswa. Sehingga mahasiswa tidak mengalami kesulitan menjelaskan berbagai hal, meskipun mereka belum pernah mengalami pengalaman tersebut. Virtual reality memungkinkan mereka untuk merasakan pengalaman yang lebih nyata. Pengalaman ini tentu menunjang pembelajaran mereka agar menjadi lebih efektif.

Science? Acta Technological Dubnicae volume 7, 2017, issue 1

Pusat Pendidikan dan Pelatihan Pengawasan Badan Pengawasan Keuangan dan Pembangunan. 2007. Audit Kinerja Sektor Publik, Pengumpulan \& Pengolahan Data

Psotka, Joseph. 1995. Immersive training systems: Virtual reality and education and training. U.S. Army Research Institute

Rheingold, H. 1991. Virtual Reality. New York: Summit.

Tomlinson, Brian. 2011. Material development in Language Teaching (2nd Ed.). Cambridge: Cambridge University Press 